\title{
Compression and representation
}

\author{
Mark Turner, Case Western Reserve University. USA
}

\begin{abstract}
Mental spaces are often connected by vital conceptual relations. When mental spaces serve as inputs to a blended mental space, the vital conceptual relations between them can be 'compressed' to blended structure inside the blended mental space. In other words, 'outer-space' relations become 'inner-space' relations. This article discusses compression of the outer-space relation of representation under mental blending.
\end{abstract}

Keywords: analogy; blending; compression; conceptual integration; mental space; representation; Winnie the Pooh

We relate one idea to another. We think of the child as related to the adult it became, through vital relations of time, change, identity, analogy, and causeeffect. Mentally, Ohio and California are connected by a conceptual relation of space. Ohio and the United States are connected by a conceptual relation of part-whole. Mary and a picture of Mary are connected through conceptual relations of representation and analogy.

For human beings, representation is one such vital conceptual relation. Whether and to what extent that conceptual relation is available to other species is a central question in cognitive science.

Suppose you are watching the rain fall, responding emotionally and intellectually to what you see. Mentally, the experience can be connected to representations of it: a film version, a sketch of the rain, a verbal description. The view of the rain and the sketch of the rain are connected by a vital conceptual relation of representation. They are also likely to be related by a vital relation of analogy: that is, the sketch is likely to share topological structures with the view of the rain.

Conceptual integration, or 'blending,' a basic mental operation at the heart of human singularity, often compresses such vital relations. Compression is a feature of conceptual integration. Many aspects of mental space networks can be compressed under blending. This article focuses on the compression of vital relations between mental spaces, and in particular the compression of the vital relation of representation.

In the case of the rain falling, we can blend the view, the sketch, and the verbal expression, all connected by vital relations. We do so by projecting elements from the 'mental space' for each to a single conceptual blend, a new mental space. The mental space for the view, the mental space for the sketch, and the mental space for the verbal expression are all connected by vital relations, and they all serve as inputs, projecting structure to the blended space. In this 
essay, I discuss how relations of representation and analogy that connect input mental spaces can be compressed into blended structures in the mental blend. Presentations of conceptual integration, vital relations, and compression are provided in Fauconnier and Turner (1998, 2000, 2002), Turner (1996, 2003, 2004, in press a) and many other works by scholars, listed on-line in Turner (2005). Compression, as a term in cognitive science, refers not specifically to shrinking something along a gradient of space or time, but instead to transforming diffuse and distended conceptual structures that are less congenial to human understanding so that they become more congenial to human understanding, better suited to our human-scale ways of thinking.

Consider Guillaume Apollinaire's poem, 'Il Pleut', an example of how an outer-space relation of representation can be compressed. In it, the lines of poetry fall downward at a slant across the page, in a way that we take as a visual representation of rainfall. The visual image of rain, the representational sketch of that visual image, and the verbal expression are mentally blended. The result is emergent structure: a sketch that can be read; writing that provides a visual representation of rain. Perceiving the view of the rain can be blended with perceiving the writing. Moreover, the reader of the text can be blended with the viewer of the rain. The sound of the rain falling can be blended with the voice of the poem. And so on through a range of evocative potential blendings.

These iconic compressions have been recognized and analyzed in aesthetics, semiotics, and narratology. Lakoff and Turner (1989) analyze an example in William Carlos Williams' 'To a Solitary Disciple'. The speaker, instructing the solitary disciple in the proper manner of perceiving the church, uses parallel sentential structures: 'Rather notice $\mathrm{x}$ than $\mathrm{y}$ ', followed by 'Rather observe $\mathrm{x}$ than y', and then 'Rather grasp. ...' But the third repetition is not closed:

\author{
Rather grasp \\ how the dark \\ converging lines \\ of the steeple \\ meet at the pinnacle- \\ perceive how \\ its little ornament \\ tries to stop them- \\ See how it fails! \\ See how the converging lines \\ of the hexagonal spire \\ escape upward- \\ receding, dividing! \\ -sepals \\ that guard and contain \\ the flower!
}


The sentence discusses the way in which the lines extend beyond their conventional bounds. We expect the converging lines of the hexagonal spire to stop at the appointed place, but they go past it. Just so, we expect the clause to stop at the appointed place, but the clause escapes its grammatical bounds. The first clause ("Rather grasp how. ..") goes beyond the expected stopping place. This is a blend of grammatical form with content. The projection of the feature of escaping bounds from the dynamic conception of the lines to the blend gives emergent structure to the grammatical form in the blend.

These blends are double-scope blends. In a double-scope integration network, the inputs have different (and often clashing) organizing frames, and the blend has an organizing frame that receives projections from each of those organizing frames. The blend also has emergent structure of its own that cannot be found in any of the inputs. Sharp differences between the organizing frames of the inputs offer the possibility of rich clashes. Far from blocking the construction of the network, such clashes offer challenges to the imagination. The resulting blends can turn out to be highly creative.

Let us consider a sophisticated case of blending between content and form. In the Provençal song 'O, Magali', embedded in Frédéric Mistral's 1858 Mireille (1966), a suitor calls from the street below to his beloved, Magali, who is in her room above. ${ }^{1}$ Magali asserts that she will escape the suitor's serenade. Her threatened means of escape is a blended story: she says she will become a fish, and swim away. She has compressed herself in the present story with the fish in the aquatic story. But the trick does not work, because the suitor imaginatively follows her into the blended story by compressing himself with something there, namely the fisherman. So she must invent a new blended story, and he must follow her again. Repeatedly, a new blended story is launched from the old. Each time, the resourceful suitor finds a way to enter the new blend through compression, and so to appear there as something related to his beloved. Here is the cascade of compressions:

- If you serenade me, I will turn into a fish and swim away in the ocean.

- If you become a fish, I will become a fisherman.

- Well then, I will become a bird and fly away.

- Then I will become a hunter and hunt you.

- Then I will become a flowering herb in the wild.

- Then I will become water and sprinkle you.

- Then I will become a cloud and float away to America.

- Then I will become the seabreeze and carry you.

- Then I will become the heat of the sun.

- Then I will become the green lizard who drinks you in.

- Then I will become the full moon.

- Then I will become the mist that embraces you.

- But you will still never have me, because I will become the virginal rose blossoming on the bush. 
- Then I will become the butterfly who kisses you and becomes drunk on you.

- Go ahead, pursue me, run, run. You will never have me. I will become the

bark of the great oak hidden in the dark forest.

- Then I will become the tuft of ivy and will embrace you.

- If you do that, you will cling only to an old oak, for I will have turned into a novice in the monastery of Saint Blaise.

- If you do that, I will become a priest and be your confessor and hear you.

Now, in Miréio this song is being recounted by Noro to the young women, who at this point tremble and beg Noro to tell them what happens to this novice, this 'moungeto', who was an oak, and a flower, moon, sun, cloud, herb, bird, and fish. Noro says, 'If I recall, we were at the place where she said she would take refuge in a cloister, and her ardent admirer responded that he would enter as her confessor, but we see again that she sets up a great obstacle':

- If you pass through the portal of the convent, you will find all the nuns walking in a circle around me, because you will see me laid out under a shroud.

This is an absolute obstacle indeed. But the suitor is undeterred:

- If you become the poor dead girl, I will therefore become the earth. And then I shall have you.

This suite of blends has a profound persuasive effect on Magali, and leads her to think about changing her judgment of the suitor's character, or at least, her response to his courtship. She says, 'Now I begin to believe that you are not merely trifling with me. Here is my little glass ring for remembrance, handsome young man.'

'O, Magali' relies on an extremely common and effective kind of compression of form and content. The rhetorical pattern of the exchange between lover and beloved is blended with the story of their prospective lives. These are radically different sorts of things. On the one hand, the future lives of the two young people are vast, uncertain, and diffuse, stretching over time and place, subject to every kind of environment, emotion, and intentionality common to the human condition. The question is, what will happen in these lives? Will they have any reliable structure?

On the other hand, and in stark contrast, the rhetorical pattern of the brief exchange has a crisp structure: two people speak in a short, witty conversation. The beloved sets a rhetorical challenge, which the suitor must meet. Each time he meets it, she sets a new challenge. She has license to jump into a new blended narrative by fiat: 'Then I will become a fish, a cloud, the sun. . '. He must take up this challenge without questioning her right to set it. He is not permitted to respond, 'Oh, you can't do that'. On the contrary, she is free to pick the next 
blend and her place in it. Nor is he allowed to become just anything. So, for example, if she says she will become a cloud, he cannot say he will become a stone. There is no conceptual success in that, and so it would fail the dynamics of seduction. Instead, he must immediately answer the challenge by finding a role for himself in the new blend that maintains the connection between him and the beloved.

Each time the beloved escapes into a new blend, the suitor follows ingeniously and to the same effect, until the beloved becomes convinced by the pattern. The pattern of the brief conversation is blended with the pattern of the extended life. The dedication of the suitor in staying with the witty conversation, always rising to the rhetorical challenge during the 10 or 15 minutes it takes to conduct the conversation, is blended with the dedication of the suitor in life, always rising to the biographical challenge of staying with the beloved through changes over years. Quite interestingly, the quality of the rhetorical performance of the suitor is taken as indicative of the biographical performance toward the beloved. Why should the beloved give the suitor her little glass ring just because he can chat like this? Why should a brief, human-scale conversation between two people have any influence on her judgment of his character and future performance as a lover? Why, in short, is she seduced?

Of course, we could answer that she was seduced at the outset and merely playing the part of reluctant maiden to maintain his interest, as is perhaps required in the culture suggested by the text. Or we could answer that verbal charm is correlated with features that make him a good mate, and so, other things being equal, her evolved psychology induces willingness to mate with someone so verbally adept. Sure, maybe.

But the answer we all recognize immediately is that she, like all cognitively modern human beings, can do double-scope blending, in this case of two radically different things, namely a brief rhetorical form and the rhythm of an extended life. Art is brief and cannot even remotely represent patterns that are diffuse in life. But it can blend our conception of such patterns with other, human-scale patterns to produce blends that count as human-scale representations of the otherwise diffuse patterns. The result is compressed blends that give us insight into what is otherwise beyond our grasp. The representation relation is so strongly compressed that in the blend, supple adherence to the challenging rhetorical form is supple adherence to the challenging lifelong emotional bond.

There is another mental conception that is being compressed into this blend. It stretches not over lives but over an act that lasts, even for 22-year-olds, only a few times longer than the conversation itself, an act of move and countermove, leading likewise to its consensual conclusion.

Seduction is a splendid and artful trick, a persuasion toward a conception of a future whose shape cannot actually be known except by taking the risk of actually living it. But in seduction through compressions of this sort, the future is blended with the rhetorical performance that refers to the future. The rhetorical representation of the future is good and true, and so, in the blend, is the future. 
The representation relation is compressed so that features of the representation become features of the future. Features of the talk become features of the life, and features of the speaker as a speaker become features of the lover as a mate. At the completion of the seduction, the future is no longer in doubt. It can be acknowledged, accepted, recommenced. The blend makes the future past, the diffuse succinct, the doubtful sure. After the seduction, there remains only to experience, over decades perhaps, what has already happened.

Complicated blending of levels is basic to human beings and not reserved for high-canon literary performances. Young children no less readily than adults compress outer-space representation relations. Disney short cartoons rely on the humor and creative pleasure that come of these compressions. In 'The Art of Skiing', a 1941 short running 7:57 minutes, a pompous, earnest, stentorian narrator in voice-over explains the elements of alpine skiing. The explanation is general, without reference to Goofy, the character whom we see. This cartoon sets up several levels of meaning and representation: the fictional activities of Goofy in the alpine environment, the animated audiovisual representation of those activities, the general conceptual frame of alpine skiing, and the narrator's verbal description of that frame, connected implicitly to the fictional activities of Goofy. Our generic understanding of voice-over description by an omniscient narrator is that it has no place inside the fictional activities themselves; it cannot be heard there. (There are many other kinds of arrangements: the voice-over can be framed as expressing the silent character's simultaneous thoughts, or the character's retrospective thoughts about this moment in time, and so on.) But in 'The Art of Skiing', the space of the narrator and the space of Goofy's activities are partially blended. We infer that the narrator can perceive the cartoon representation from his evident increasing frustration at Goofy's radical failure to perform as described. At one point, the narrator is discussing how the alpine skier leaps from his bed at sun-up in joyous anticipation of the thrills that lie in store for him. But Goofy is dragging. He puts on his skis, but then goes back to bed. The narrator says, 'And now. . . and now. . . but Goofy is snoring. So the narrator yells 'NOW!' and Goofy hears. It also seems that Goofy can understand at least part of what the narrator says. When the narrator, having described the sequence of dressing, says, 'Now, we are completely dressed. .' Goofy seems to have been misled into thinking that he is fully dressed, and heads out, so the narrator must add, 'with the exception of the trousers', and Goofy, embarrassed at wearing no pants, slinks back to try to put his trousers on over his skis. Routinely in this cartoon, separate mental spaces connected by a representation relation are compressed into a blend in which the separation is not maintained.

The Disney enterprise has produced one tour de force after another of blending across levels. 'Winnie the Pooh and the Blustery Day', a Walt Disney classic that won an Academy Award in 1968 for 'Best Cartoon Short Subject', requires the child to blend multiple levels repeatedly. Inside any of these levels, there is already elaborate blending. Let us pause to pick out just a few of these blends, as a token indication of the wonders of blending and compression. 
Owl tells Pooh and Piglet that his aunt visited her cousin, who, being a screech owl, sang soprano in the London opera. The cousin's constant practicing so unnerved Owl's aunt 'that she laid a seagull egg by mistake'. This blend works inside the level of the fictional world of Winnie the Pooh, without involving the kinds of compressions of representation relations that we will inspect below. To create the reality of that fiction, owls are blended with human beings to produce talking owls. As I have discussed in The Literary Mind (1996), the voices of talking animals typically arise by projection not only from human beings but also from the noises made by the kind of animal in question: so it is fitting that a talking 'screech' owl in the blend would be prone to bad operatic performances. Now for the mistaken egg part. We have a notion that a mother bird gives birth to eggs belonging to her species. We have a notion that distressing conditions, including sounds, can conduce to mistakes, whether in thought or action. We also have the notion that environmental causes afflicting the mother can lead to misbegotten offspring. If we blend these notions with Owl's talking aunt, we can produce a conception in which distress and shock lead a mother to a misbirth. This is a mistake produced by blending intentionality with procreation: instead of a mistake in intentional thought and action, she commits a mistake of procreation: she lays a seagull egg.

One more: the wind blows Piglet so hard that eventually he becomes airborne. Pooh grabs Piglet's scarf to rescue him. It unravels to become a string, with Piglet at the end of it, like a kite. Given the aerodynamics of Piglet's form and the blusteriness of the wind, this would be impossible under everyday physics, but Disney cartoons specialize in such 'plausible impossibilities,' where a realworld constraint is not projected to the blend, so the blend achieves the plausible physical impossibility. (We have all seen Daffy Duck's head, when slapped, spin on its axis several times before rotating back, presumably driven in reverse by the potential energy stored up in highly elastic neck muscles.) Roo says to Kanga, 'Look, Mom, look! A kite!'. The Piglet-kite is a blend we can easily recognize to be a blend. But at just the moment of Roo's call to his mother, there is an equally complicated but unnoticed bit of blending: the viewpoint shifts so that now we are 'looking through Roo's eyes' and focusing on the Piglet-kite. Visual and literary representations always carry an implicit point of view and focus for the audience. As we watch, hear, or read, we respond to usually unnoticed prompts to move our viewpoint and our focus. In the case of 'looking through Roo's eyes', we understand the visual representation as compressing our viewpoint and focus with Roo's, for just a few seconds, before we move to a different compression.

The famous dream sequence involving 'Heffalumps and Woozels,' complete with such classic integration network props as mirrors and spirits, offers an amazing sequence of 'in-the-fictional-reality' blends that could support a study in themselves.

Here are some of the levels in 'Winnie the Pooh and the Blustery Day,' many of them already hyper-blends (that is, a blend with an input that is a blend), themselves:

- The perhaps fictional activities of a boy with his toys, including stuffed 
animals. In the opening credits of 'The Many Adventures of Winnie the Pooh' (which includes 'Winnie the Pooh and the Blustery Day as a 'chapter'), we see in the background a non-animated boy's bedroom, which contains stuffed toys that obviously correspond to the animal characters we will see in the animated cartoon that follows. For something to count as a 'stuffed animal', it must already be a material anchor for a conceptual blend in which inanimate stuff is blended with an organism or a generic concept of an organism. Achieving this blend does not mean that we are deluded. But the blend is psychologically powerful and useful.

- The fictional activities of Christopher Robin, Winnie the Pooh, Eeyore, Piglet, Owl, Kanga and Roo, Rabbit, and others. The blending needed to produce this fictional world is elaborate. To achieve it, the already blended stuffed animals are blended with concepts of both animal and human behavior. The landscape and environment also show sophisticated blending.

- The mental and psychological states of all these characters.

- A. A. Milne's stories representing these fictional activities.

- The writing that expresses those stories and also presents a frame-story about the 'real' boy who is the 'basis' of the stories. It is presumably this boy's bedroom we are seeing in the opening credits to 'The Many Adventures of Winnie the Pooh'.

- A person who reads these stories aloud.

- A child to whom these stories are read.

- The printed and bound book that includes that writing. Interestingly, the boy's bedroom represented in the opening credits includes a copy of this book.

- The static illustrations in the bound book of the fictional activities of the characters.

- Our imaginary perception of these activities in the mind's eye, prompted by the verbal and printed representations.

- The perception of such a book as we turn its pages.

- The film, representing many of these levels, from the boy's bedroom to the fictional activities of the characters.

- The voice-over narrator, whose voice is represented in the film.

- Music, which, through blending to achieve compressions, we can interpret as 'programmatic' and as carrying 'mood' and 'tone'. (For a discussion, see Freedberg (in press) and Zbikowski [in press].)

- And very many others. E.g. in the DVD version there is a 'menu' that allows one to select scenes. Merely dealing with this menu involves elaborate compressions of levels.

Now let us survey some of the blending of levels that involves compression of representation links.

- The static illustrations in the book are connected by representation relations to the dynamic fictional events they represent. In 'Blustery Day,' we see a copy of the book, and as the pages are turned, we see illustrations. Periodically, one 
of the illustrations becomes animated. This blend compresses features of the represented scene with the illustration, to give an animated illustration in a printed book. This very cleverly provides the transition in 'Blustery Day' from the book to the animated cartoon. We zoom in on the now animated illustration until we lose the frame of the printed book and are immersed in the animated representation of the fictional reality.

- The talk in the fictional reality is blended with the now animated, previously static illustrations so that the characters in the illustrations not only move but also speak.

- The voice of the person reading the words on the pages (we can see the pages turning in the cartoon) is compressed with the voice-over of the narrator of the cartoon. At various points, we can see that although the voice-over is speaking some of the words on the printed page, he is in fact abbreviating considerably.

- The level containing the voice of the reader/narrator is on occasion blended with the level of the fictional reality and the book: when the voice starts talking about 'the next chapter', Pooh says, 'but I haven't finished yet!' and the narrator replies, 'But Pooh, you are in the next chapter'. But this is also blended with the level of the book: the page containing the now animated illustration is occluded because the page has been turned to the next chapter; Pooh's voice comes from that animated illustration in the book, and so the page is partially turned back so we can see Pooh speaking. This compresses the fictional reality, the inside of the book, and the world outside, since Pooh is in fact leaning to see past the half-turned page that would occlude his view of the person reading the book.

- The fictional reality is compressed with the space in which the book is being read: when the wind blows in the blustery day, and we are seeing the book within the cartoon, the wind turns the page of the book! This compression is helped by the prior blend of the fictional reality with the static illustration, so that the now animated illustration has projected to it movement and sound from the fictional reality, and if there is 'wind' and the sound of wind already 'in' the page we are looking at as the pages are being turned, our notion that wind can move in a continuous physical environment makes intelligible the movement of the wind off the page and into the space in which the book is being read, to turn the page. This blending is subtle here, but is used to noticeable effect in the prior Winnie the Pooh cartoon: when Winnie is catapulted 'in' the now animated illustrations, Gopher says 'Sufferin' succotash, he's sailing clean out of the book! Quick! Turn the page!'. The turning of the page makes it possible for Pooh to land in a suitable place 'back' in the book, which is simultaneously the fictional reality.

- The elements of the fictional reality, compressed with the now animated illustrations, can be compressed with the elements of the rest of the printed book. When the wind blows, it blows the leaves gradually off the tree, and then the letters printed on the page are blown just as the leaves are blown. In the animated illustration in the book, the huge rain cloud releases the rain 
into the lake, which is above the text. This influx drives the water right down the page, which swamps and displaces the letters to the bottom of the page (but not, this time, out of the book).

When Tigger leaves Pooh's house, he is singing his signature song:

The wonderful thing about Tiggers

Is Tiggers are wonderful things

Their tops are made out of rubber

Their bottoms are made out of springs

They're bouncy, trouncy, flouncy, pouncy

Fun, fun, fun, fun, fun

But the most wonderful thing about Tiggers is

I'm the only one

I'm the only one.

At 'trouncy', Tigger bounces from the animated reality into the now animated illustration in the book, suggesting that the animated reality and the book are alternative views on the same world. As he goes over the horizon, the printed lyrics lie above the illustration into which he has bounced - except that the last line of the lyrics ('I'm the only one') is not yet on the page. As Tigger sings this last line, the words in 'I'm the only one' appear one after another from beyond the horizon. The movement of the printed words is compressed with the travel of his voice back above the horizon and toward Pooh's viewpoint. The printed words travel up to take their appropriate place in the book! So the activity of the fictional reality is compressed with the text itself, and causality in the fictional reality is compressed with causality for the book and its print.

Conceptual integration is a basic mental operation. Its most advanced form, double-scope integration, is a hallmark of the way we think. Under double-scope integration, the blending of input mental spaces is often accompanied by compression of vital relations between them. Powerful, nuanced, and mentally inexpensive, the compression of representation is a forge of creativity yet child's play for our species. Human beings lie on a gradient with other cognitively sophisticated animals, and this is crucial in many ways. But our capacity for double-scope integration places us in a different mental galaxy.

We're the only ones.

Notes

1 See pages 112-23. I am grateful to Manuela Carneiro da Cunha for bringing this poem to my attention. 


\section{References}

Fauconnier, G. and Turner, M. (1998) 'Conceptual Integration Networks', Cognitive Science 22(2): 133-87.

Fauconnier, G. and Turner, M. (2000) 'Compression and Global Insight', Cognitive Linguistics 11(3-4): 283-304.

Fauconnier, G. and Turner, M. (2002) The Way We Think: Conceptual Blending and the Mind's Hidden Complexities. New York: Basic Books.

Freedberg, D. (in press) 'Composition and Emotion', in M. Turner, (ed.) The Artful Mind New York: Oxford University Press.

Lakoff, G. and Turner, M. (1989) More Than Cool Reason: A Guide to Poetic Metaphor. Chicago, IL: University of Chicago Press.

Mistral, F. (1966) Mireille, in P. Rollet, (ed.), Euvres Poétiques Complètes, vol. 1, pp. 14-456. Barcelona: R. Berenguié. (Originally published 1858).

Turner, M. (1996) The Literary Mind: The Origins of Language and Thought. New York: Oxford University Press.

Turner, M. (2003) 'Double-scope Stories', in D. Herman, (ed.) Narrative Theory and the Cognitive Sciences, pp. 117-42. Stanford: CSLI Publications.

Turner, M. (2004) 'The Ghost of Anyone's Father', in G. Bradshaw, T. Bishop, and M. Turner (eds) (2004) The Shakespearean International Yearbook 4: Shakespeare Studies Today, pp. 72-97. Aldershot: Ashgate.

Turner, M. (2005) The Blending Website: http://blending.stanford.edu.

Turner, M. (in press a) 'Compression and Art', in M. Turner, (ed.) The Artful Mind New York: Oxford University Press.

Turner, M. (ed) (in press b). The Artful Mind. New York: Oxford University Press. See http://theartfulmind.stanford.edu.

Zbikowski, L. (in press) 'The Cognitive Tango', in M. Turner, (ed.) The Artful Mind New York: Oxford University Press.

\section{Address}

Mark Turner, 10900 Euclid Avenue, 714 Crawford Hall, Case Western Reserve University, Cleveland, OH 44106, USA [http://markturner.org] 
